\title{
THE MICROEMULSION AS A KEY PLAYER IN CONQUERING THE SKIN BARRIER FOR THE AIM OF TRANSDERMAL DELIVERY OF DRUGS: REVIEWING A SUCCESSFUL DECADE
}

\author{
RANIA YEHIA*, DALIA A ATTIA \\ Department of Pharmaceutics and Industrial Pharmacy, The British University in Egypt, Cairo, Egypt. Email: rania.yehia@bue.edu.eg
} Received: 07 February 2019, Revised and Accepted: 09 April 2019

\section{ABSTRACT}

Microemulsion (ME) systems are now considered of the most successful transdermal drug delivery systems. This is due to their nanodroplets size in the one hand and to their composition that enables the use of several mechanistically penetration enhancers in the same formulation on the other hand. This work summarizes the types, properties, and the merits of the use of MEs for transdermal delivery and reviews the successful studies that were performed to deliver several drugs through this important route during the past 10-12 years.

Keywords: Transdermal delivery, Skin penetration, Penetration enhancing, Advanced drug delivery systems, Microemulsion.

(C) 2019 The Authors. Published by Innovare Academic Sciences Pvt Ltd. This is an open access article under the CC BY license (http://creativecommons. org/licenses/by/4. 0/) DOI: http://dx.doi.org/10.22159/ajpcr.2019.v12i5.32444

\section{INTRODUCTION}

Pharmaceutical researches lead to finding and innovating new drug moieties. Yet, most of them exhibit poor solubility in the gastrointestinal tract associated with undesired pharmacokinetic properties. This directed the efforts toward the development of new drug delivery systems. To solve these serious problems, several approaches were introduced. One of them is the usage of lipid-based systems for instance: The microemulsions (MEs) [1].

The term "ME" was first introduced in the 1940s by the researchers Hoar and Schulman; where the ME was formed by titrating of an ordinary milky emulsion with hexanol [2]. From now then, the use of MEs for the delivery of drugs through the different routes of administrations and specifically, the transdermal route has never ceased.

The skin is considered a natural feat and the hardest barrier to cross in the body. However, MEs with its main components comprising several penetration enhancers were proven to offer an encouraging platform for the transdermal permeation of both lipophilic and hydrophilic active moieties [3].

This review will summarize the successful studies and trials in the past decade that was able to deliver drugs possessing different and various natures through the skin using ME preparations.

\section{SKIN}

\section{The skin structure and its barrier function}

The skin main function is to shield the body against exposure to multiple factors such as ultraviolet radiations, chemical pathogens, and free radicals [4]. Besides, the skin ought to secure the thermoregulation through fluid transpiration (sweating), as well as the gases and toxins exchange process with the external environment [5]. According to the aforementioned functions, expectedly, the skin structure is constructed to provide a very hard barrier.

The skin thickness is, in general, a few millimeters and is a multilayered organ. The skin layers were mainly differentiate into three main parts the outer most epidermis, under which lays the intermediate viable dermis, then followed by the subcutaneous fat tissue; known as the hypodermis [6]. The arrangement of the outer cell layers is according to the famous "brick and mortar" model $[7,8]$.
The outer epidermal layer has been subdivided into multiple strata; four to be exact. This division was based on the differentiation of the cells in the layer. The outermost cells tend to be more keratinized and elongated with loss of the cells' nuclei forming flattened corneocytes of the first strata, and then in the following strata the cells become better differentiated till we reach innermost cells.

The "bricks" are the corneocytes of the hydrated keratin, surrounded by multiple lipid bilayers of ceramides, fatty acids, cholesterol, and cholesterol esters known as the "mortar." This mighty structure of the skin denotes the key barrier to the penetration of various moieties through the skin $[9,10]$. The lipid bilayers are organized with inbetween distance around 6-13 nm, forming regions of semicrystalline gel and liquid crystal domains that contribute to the impermeability of the skin $[11,12]$. In addition, stratum corneum (SC) acts as a barrier against the loss of water from deep tissue layers, which leads to skin surface softness under varied atmospheric conditions [10].

The second layer laying underneath the epidermal layer is the dermis; it is a hydrophilic layer which is rich in collagen and elastic fibers and is greatly thicker than the epidermis (typically $1-4 \mathrm{~mm}$ ). It additionally comprises mechanoreceptors and appendages together with blood vessels [13].

As for the third subcutaneous fat tissue layer, it is mainly composed of loose connective tissue and fat lobules (assembled fat cells). The main role of this layer is to store fat, and thereby act as a protectant against external physical pressure and generates heat. Furthermore, one of the important characters of this layer is to convey the vascular and neural systems for the skin [14]

\section{Skin penetration pathways}

The dermis layer is the main site for the absorption of molecules. Therefore, to reach it, the breaching of skin barrier function is required. Previous studies have revealed that there are three leading penetration pathways transcellular (intracellular), intercellular, and through skin appendages (follicular and their associated sebaceous glands together with the sweat ducts) [3].

The intracellular route is assumed to be the more complex, given that the molecules movement from a cell to the underlying one, requires the crossing of the lipid bilayers and thus the molecules must attain adequate lipid-water partitioning properties [15]. The skin appendages 
routes have been assumed to be insignificant for a long period of time due to its minute skin area (around 0.1\%) [15]. However, lately more thoroughly investigates of this penetration mechanism propose a higher significance especially for follicular route [16]. As for the intercellular route the molecules pass through the small spaces between the corneocytes, which makes this route more challenging [14].

In whichever circumstances, the privileged route for permeation depends mainly on the physical and chemical characteristics of the penetrating molecule, specifically the molecular weight (MWT), the partition coefficient, the molecular volume, and solubility. As an example, in case of regular circumstances macromolecules (Mwt $>500$ Da) could not pass through the skin barrier, only some specific methods are capable of overcoming this limit [17]

\section{Transdermal delivery}

There are multiple advantages for transdermal delivery. The avoidance of hepatic first-pass effect [18] together with stomach irritation and ulceration [19], in addition to the known tiresomeness of recurrent parenteral administration [18]. Besides, it offers a substituent route for patients who are incapable of taking drugs orally; for example, nauseated and unconscious patients. Other advantages include the ease and much more convenient method of administration for the patient offering a better chance for patient compliance, with the ability of instantaneous withdrawal of the treatment when necessary. Moreover, it facilitates sustained delivery, achieving a steady-state profile [20].

On the other hand, there are some limitations for the transdermal route including local irritation, local edema, and itching especially at the site of application, in addition to erythema which may occur due to the active molecules, the adhesive, or other excipients in the formulation. In addition to, the skin's low permeability which restricts the quantity of active moieties that can be transported transdermally [14].

To evaluate the transdermal permeation of different active moieties and preparations, Fick's second diffusion law is used. It quantifies the drug penetration efficacy, which is stated as "the cumulative amount of drug (Q) transported across the skin barrier per unit area as a function of time $(\mathrm{t})$ "[21].

$$
Q=\operatorname{KHCveh}\left[\left(\frac{D}{H^{2}} t-\frac{1}{6}-\frac{2}{\pi^{2}} \sum_{n=1}^{\infty} \frac{(-1)^{n}}{n^{2}} \exp \left(\frac{-D n^{2} \pi^{2} t}{H^{2}}\right) .\right.\right.
$$

Where, Cveh is the drug concentration in the donor solution, $\mathrm{n}$ is the iterative number, and $\mathrm{K}$ is its $\mathrm{SC}$ formulation partition coefficient; $D$ is the diffusivity of the drug in the SC of thickness $\mathrm{H}[22,23]$. Other parameters could be deduced from the law such as partitioning $(K H)$ and diffusivity $\left(D / H^{2}\right)$. In turn, the permeability coefficient $(k p)$ of the drug across the skin was calculated as follows:

$$
K p=(K H) \times\left(\frac{D}{H^{2}}\right)=\frac{K \cdot D}{H}
$$

In addition to, the estimated steady-state drug flux (Uss) [21].

$$
J s S=K p \times C v e h
$$

Equation (3)

This model proposes the key approaches to improve drug penetration are (Moser et al., 2001): (1) Enhancing the drug solubility in the SC, (2) increasing the diffusion coefficient, and (3) increasing the ratio between the drug concentration and its solubility in the vehicle (supersaturation); aqueous solubility $>1 \mathrm{mg} / \mathrm{ml}$ [24]. Still, the explanation of the permeation with this method is elementary as its main drawback is not considering the highly complicated routes and barriers that face the drug moieties while penetrating the skin [25].

Pertaining to the previous, transdermal drug transport needs to be abetted. It could be increased by manipulating the barrier function through either physical or chemical methods. Those methods lead to widening or multiplication of the pathways for dermal microcirculation. The physical methods include the exposure of the SC to mechanical stimuli (sonoporation/sonophoresis), a strong electrical stimulus (electroporation/iontophoresis), thermal stimulus, microporation, needleless injection, magnetophoresis, radiofrequency, pressure wave, and medicated tattoos $[14,26]$. As for the chemical methods: The use of suitable skin penetration enhancers such as alcohols and polyols (ethanol and propylene glycol), sulfoxides (dimethyl sulfoxide), fatty acids (oleic acid), surfactants (Tween, Span, and sodium lauryl sulfate), amines and amides (Azone and $\mathrm{N}$-methylpyrrolidone), terpenes (limonene), and esters (isopropyl myristate) were developed over the past years. In addition, water was used as penetration enhancer through improving the hydration of the SC $[26,27]$.

Penetration enhancing through formulation approaches have been used widely, especially lately the usage of colloidal carriers as transdermal drug delivery systems over the conventional ones. Multiple types of colloidal carriers have been studied including solid lipid nanoparticles [28], liposomes, nanostructured lipid carriers, dendrimers, niosomes, ethosomes, transfersomes, nano, and microemulsion [14].

It has been broadly established that the use of MEs in comparison to other formulations widely enhance transdermal permeation of drugs [29-31]. Therefore, we are going to further discuss the ME in more particulars.

ME

\section{ME structure and components}

Hoar and Schulman were the lead researchers in ME preparation; it goes all the way back to 1940 s. It started with a simple titration to an ordinary milky emulsion using hexanol [2] and has developed broadly ever since.

MEs are heterogeneous systems consisting of no $<1$ immiscible liquid dispersed in another. The dispersions are formed when oil, water, and surfactant/cosurfactant are mixed in appropriate proportions. They are arranged in the form of droplets with the aid of a surfactant either forming oil-in-water $(\mathrm{O} / \mathrm{W})$ or water-in-oil $(\mathrm{W} / 0)$ emulsion. The stabilization is typically performed by an interfacial film of surfactant(s) and cosurfactant(s). The ME systems are constructed using "pseudoternary phase diagram," where each apex of a triangular phase diagram represents component oil, water, and the surfactant and cosurfactant is jointly taken as a single phase and is located on one apex [32].

Accordingly, MEs are described as an isotropic thermodynamically stable mixture formed of oil, water, and an amphiphilic mixture [33]. The core dissimilarity between the ordinary emulsions and micro ones lies in the shape and size of the droplets dispersed in the continuous phase; emulsions can be classified into: Macroemulsion (droplet size $>400 \mathrm{~nm}$ ), nanoemulsion (droplet size 100-400 nm), and ME (droplet size - 10-100 nm) [34]. Other important differences between MEs and the ordinary emulsions are that the MEs are kinetically thermodynamically stable, clear translucent; as a result of the minute size of the droplets with lay below the range of wavelength for visible light, and simpler with low energy input method of preparation. On the other hand, emulsions are cloudy, thermodynamically unstable and require large energy input to prepare. This would eventually lead to phase separation $[32,35]$.

Furthermore, emulsions are known for the fixed shape of spherical droplets in dispersion while the ME varies between multiple structures from micelles to bicontinuous without exact distinction [36]. In relation to Winsor [37] classification, there are four forms of ME phases that are existent in equilibrium; these phases are denoted as Winsor phases $[32,38,39]$.

- Type - I (Winsor I); it consists of O/W MEs, where oil droplets are surrounded by a film of surfactants and cosurfactants forming the internal phase and distributed in water as the continuous phase 
- $\quad$ Type - II (Winsor II); it consists of W/O MEs, where water droplets are surrounded by a film of surfactants and cosurfactants forming the internal phase and distributed in oil as the continuous phase

- Type - III (Winsor III or middle-phase ME); it consists of a bicontinuous ME system. In this case, both water and oil exist as a continuous phase. An irregular channel of oil or water exists, and seems like a "sponge phase." The transitions between $\mathrm{O} / \mathrm{W}$ and $\mathrm{W} / \mathrm{O}$ MEs may pass through this bicontinuous state. They may show nonNewtonian flow and plasticity

- Type - IV (Winsor IV or single phase homogeneous mixture); a singlephase (isotropic) micellar solution, with oil, water, and surfactant that are all homogenously mixed.

Fig. 1 shows a schematic diagram for the ME systems types.

The components of the ME system includes the oily phase, aqueous phase, surfactants, and cosurfactants.

\section{The oily phase}

The selection of appropriate oily phase is important as it influences the selection of the other ingredients of the ME. The oil component has great influences on the curvature of the system as it has the ability to penetrate the tail area and hence causes the swelling of the tail group region of the surfactant monolayer. The oils having long chain alkanes have lower penetration ability to the tail group region. Yet, the ones with shorter chain alkanes can penetrate it to a greater extent, and therefore cause swelling of tail group region to a larger extent, causing an increase in the negative curvature (and lowered effective hydrophilic-lipophilic balance [HLB]) [40]. There are various types of oils largely employed in the preparation of MEs; saturated fatty acid such as myristic acid, lauric acid, and capric acid, as well as unsaturated fatty acid, for instance, linoleic acid, oleic acid, and linolenic acid, which have their own penetration enhancing the property. In addition to the usage of fatty acid ester-ethyl or methyl esters of lauric, myristic and oleic acid [41]. The most prevalent enhancer is oleic acid as the unsaturated cis configuration perturbs the lipid packing more than does the trans configuration [42]. Penetration enhancement effect of the fatty acids is based on the fact that they penetrate the hydrophobic SC bilayer and perturbs it by generating separate domains, and in this way may induce highly permeable pathways in the SC [30].

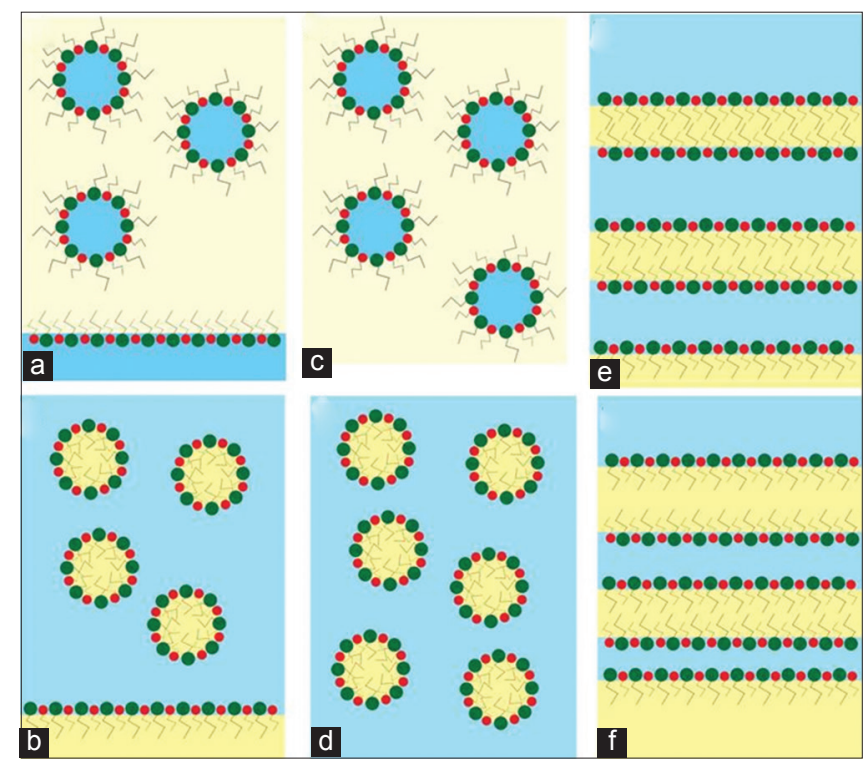

Fig. 1: Schematic representation of the microstructures of microemulsion (ME) systems. (a) Type - II (Winsor II) W/O ME, (b) Type - I (Winsor I) 0/W ME, (c and d) Type - IV (Winsor IV or single-phase homogeneous mixture), (e and f) Type - III (Winsor III) bicontinuous ME (e - water-rich, f - oil-rich)

\section{The aqueous phase}

The most universally used aqueous phase is water [38,43-45]. The aqueous phase can contain both preservatives and hydrophilic active ingredients [38]. Some researchers used buffered solutions as the aqueous phase $[46,47]$. Only due to the considerable effect on the phase behavior of MEs, the $\mathrm{pH}$ of the aqueous phase always needs to be altered. As in the case of the MEs used for the parenteral administration, the aqueous phase must be iso-osmotic to the blood which is adjusted by dextrose, sodium chloride, glycerol, and sorbitol [38]

\section{Surface Active Agent (SAA)}

They are the substances which exhibit superficial or interfacial activity, where they lessen the tension to a very low value that consequently will further enhance the dispersion process throughout the formation of the ME in addition to helping in providing a flexible film. They are amphiphilic molecules with a polar head and a non-polar (hydrophobic) tail. The surfactants that are utilized to stabilize ME systems may be: (1) Non-ionic, (2) cationic, (3) amphoteric, or (4) anionic surfactants. Amphoteric surfactants such as egg lecithin and soy lecithin are considered as natural ingredients and hence are widely used for their low toxicity [48]. Combinations of surfactants, mostly ionic and nonionic, can be very effective at increasing the extent of the ME region [35]. Selection of a proper surfactant is the key to the formation of any ME. In general, hydrophobic surfactants $(\mathrm{HLB}<10)$ will be suitable for the formation of W/O MEs, and the hydrophilic surfactants (HLB>10) will form 0/W ME $[41,49]$.

Non-ionic surfactants are very often used in pharmaceutical ME formation. They are considered a beneficial alternative to natural surfactants as they are of low toxicity, low irritancy, and biodegradability $[35,41]$; for example, polysorbates including Tweens (polyoxyethylene sorbitan-akyl esters) which are well known and widely used [30]. Other used surfactants include propylene glycol caprylate (Capryol 90 ${ }^{\circledR}$ ) [50], Labrasol ${ }^{\circledR}$ [51], and Plurol Oleique ${ }^{\circledR}$ [52].

In most cases, surfactants solely are not capable of reducing $0 / \mathrm{W}$ interfacial tension considerably to facilitate the formation of MEs $[53,54]$.

\section{Cosurfactants}

The presence of cosurfactants is a key factor in giving the significant flexibility of the ME surface, by reducing the interfacial tension and increasing the fluidity and the entropy of the system [35,55]. The main consequence of this is attaining curvatures that are necessary for the MEs formation $[35,40,56]$. The cosurfactants are integrated into interfacial films; however, they are incapable of forming micelles on their own, and the presence of surfactant is crucial for that process. Usual cosurfactants as reported in literature in colloid science are molecules that are formed of a small polar head group together with an alkyl chain of a suitable length (short chain C2-C10), for example n-hexanol, n-octanol, and n-pentanol [49]. Ethanol, sorbitol, and propylene glycol are among the most commonly used cosurfactants in the transdermal formulation and their use was reported to improve the flux of several drugs $[57,58]$. Furthermore, diethylene glycol monoethyl ether (Transcutol $\mathrm{P}^{\circledR}$ ) was used as a cosurfactant due to its nontoxic powerful solubilizing properties in both dermal and transdermal routes $[30,59]$.

The composition of the ME provided it with multiple benefits to be able to use it as a carrier system for the delivery of active moieties. They are thermodynamically stable systems. They act as a super solvents that can solubilize both hydrophilic and lipophilic molecules such as food additives, nutraceuticals, aromas, cosmetic compounds, active ingredients, and drugs [32,38,59,60]. Furthermore, it provides protection from the hydrolysis and oxidation as the presence of the drug in the oily domain of an 0/W ME is not exposed to water and air attack. MEs are easy to formulate and scale up (zero interfacial tension and spontaneous formation). Furthermore, pertaining to the increased 
efficacy of the active moieties by the use of MEs, it allowed the reduction of the total dose administered and hence lowering of the side effects. Moreover, these systems can be used for the purpose of controlled release of the drugs and drug targeting. In addition, the drug release could reach pseudo-zero-order kinetics; this depends on the present amount of the dispersed phase, the transport rate together with the partition of the active moiety $[32,38,59,60]$. Regarding the transdermal permeation specifically; the composition of the ME is a key factor for the modification of the diffusional barrier of the skin as the components act as permeation enhancers [61].

As for the disadvantages of ME based systems they include: The presence of large amount of surfactant and cosurfactants to stabilize the droplets and hence, nontoxic surfactant should be used for pharmaceutical applications. In addition to, ME systems have minute solubilizing capability for substances with high-melting points that might be used in the system [32,39]. They also have no solubilizing power for minerals such as iron and calcium and if added to a ME system, would likely result in a suspension, thereby they cannot be incorporated into ME [34]. Furthermore, due to their low viscosity they have limited topical application solely they usually require their incorporation into another dosage form [62]. Furthermore, MEs are sensitive to temperature and salinity changes any change in them may cause phase changes, which may lead to phase separation [34].

\section{Rational of the use of MEs in transdermal delivery}

The capability of ME to boost the transdermal delivery of active moieties is affected by multiple consistent factors for instance: The ME microstructure (for example, size, type, and shape) in addition to the ME formulation itself and the ratio of each constituent $[30,36]$. The location of the drug in the ME microstructure, whether imbedded in the matrix or located at the interface affects the transport efficiency of the moieties. ME components have been known to be able to act as penetration enhancers [27], by altering, fluidizing and disrupting the lipid arrangement of the SC or else by increasing the partition coefficient between vehicle and skin $[1,21,31,59,63]$. There is a relative association between the degrees of disruption for the SC caused by certain ME component, and the amount of this component present in the skin [31]. The water content in ME has been found in many studies to be able to cause a hydration effect [64] and due to that effect an enhancement for penetration occurs $[27,45]$.

Some of the constituents of the oil phase of the ME thwart the loss of water molecules from the deepest layers of the skin. For instance, vegetable oils have the ability to alter the water proportion in the upper skin layers pertaining to their well-known occlusive power [31,65], and yet oleic acid can induce disruption and phase separation to the SC lipids producing fluid domains within them [59]. In general, the transdermal penetration of the hydrophilic moieties might not be boosted by the formerly stated occlusion effect; instead, it could cause skin irritation [66]. The appropriate combination of the lipophilic and hydrophilic components effects would lead to an increase of the enhancing efficacy of the entire system. Surfactants principally the anionic ones [27] can cause SC disruption, which is consequent to the binding with keratin filaments present in the bricks of the skin, i.e. the corneocytes [67]. Accordingly, the SC structure disintegrates, enabling the permeation $[27,30]$, and the diffusion coefficient increases [68].

\section{REVIEW OF LITERATURE ON DIFFERENT ME FORMULATIONS FOR TRANSDERMAL DELIVERY}

The following section will discuss several examples of drugs mentioned in literature that were incorporated in ME systems for transdermal delivery through approximately the past decade, and they are summarized in Table 1.

In 2005, 5-fluorouracil was hydrophilic drug, used as an antineoplastic. It was encapsulated in W/O ME containing isopropyl myristate (IPM) as oily phase, water aqueous phase, and an anionic surfactant aerosolOT (AOT or sodium bis (2-ethylhexyl) sulfosuccinate). AOT produces
W/O ME in non-aqueous medium. Mainly the aim of this study was to investigate the effect of AOT and water concentrations on the in vitro transdermal permeation. This was performed using a reformed Keshary and Chien diffusion cell through hairless mouse skin. Increasing the water ratio increases from 5 to 15 the flux increases significantly, however, the increase of water ratio from 15 to 20 showed a very slight increase in flux. Using constant water content $\mathrm{W} 0=15$, the MEs having 5:95, 9:91, and 13:87 weight ratio of AOT: IPM provided 3.58, 5.04 , and 6.3-fold enhancement of 5-fluorouracil, respectively. This lead to concluding that increasing the AOT ratio leads to an increase in the corresponding flux. The results of this study revealed that the ME affects the components of the SC and fluidize its architectural structure. This interaction is influenced by the concentrations of water and AOT in the ME [69].

In 2006, meloxicam the famous nonsteroidal anti-inflammatory drug (NSAID) was formulated in the form of ME. The main purpose of the study was to find out the best composition for ME to reach maximum transdermal flux. To achieve this; first, the solubility of meloxicam indifferent oils (IPM, ethyl oleate, Cremophor ${ }^{\circledR}$ EL, Oleic acid, and Triton $\mathrm{X}-100$ ) and in non-ionic surfactants (Labrasol ${ }^{\circledR}$, Tween 20, Tween 80, and Tween 85) have been investigated. Although the meloxicam showed the high solubility in oleic acid compared to other oils, the highest solubility achieved was with Tween 85 . Second, the selection of the best combination of oily phase and surfactant/cosurfactant was performed through constructing pseudo-ternary phase diagram and choosing the combination showing the highest ME domain. The short-chain alcohols together with Transcutol P were tested as cosurfactants in combination with Tween 85 as a surfactant. Oleic acid, IPM, and ethyl oleate were investigated for the oily phase. The selected combination was IPM/ Tween85/ethanol/water. This was pertaining to previous reports that the HLB of oils and surfactant are equal, the best-emulsified effect is achieved; knowing that, here in this case, the HLB of IPM is 11.1 similar to that of Tween 85 (11.0). Furthermore, ethanol was selected, since the small volume of short-chain alcohols made them capable of being inserted into the interfacial layer, and thereby form a tighter film. Finally, the influence of the percentage of IPM (5\%, 10\%, and 15\%) and the effect of SAA/coSAA (1:1) with the mass ratio $40 \%, 50 \%$, $60 \%$, and $70 \%$ on the permeation of meloxicam through the skin were assessed in vitro utilizing excised rat skins. The low percentage of oil was preferable as by increasing the oil amount the droplet size increase, also due to the hydration effect of the water present in the ME causing the swelling of the corneous cell and consequently the drug channels to widen. In addition, on decreasing the percentage of surfactant mixture present in ME from 70 to $50 \%$, the rate of permeation of the meloxicam through excised skin was increased. This was attributable to the elevated thermodynamic activity of the drug in ME at the lower content of surfactant, despite that, the $40 \%$ showed lower permeation rate than the $50 \%$ this was because the formula was on borderline of the domain for ME. Therefore, the selected optimum formulation scoring the highest skin permeation rate $\left(5.40 \mu \mathrm{g} / \mathrm{cm}^{2} / \mathrm{h}\right)$ was $0 / \mathrm{W}$ and consisted of $50 \%$ Tween 85 /ethanol (1:1), 5\% IPM, and $0.375 \%$ meloxicam and water [70].

In 2007 and 2008, a research group conducted studies on some local anesthetics lidocaine, dibucaine, tetracaine as well as their corresponding hydrochloride salts (model drugs); knowing that the salts are the hydrophilic forms of the drugs contrary to their original base in hydrophobic forms. The main target of the studies was to explore the effect of various ME types on the in vitro skin permeation of the model drugs. In addition to, characterization of their associated physicochemical properties of the model drugs loaded in two different types of MEs which are: $0 / \mathrm{W}$ and W/0.12 formulations were prepared in each year. The MEs were prepared using $45 \% \mathrm{w} / \mathrm{w}$ surfactant mixture of Brij 97 and 1- butanol (2:1) in 2007 while using AOT and 1-butanol with ratio 2:1 in 2008. In both 2007 and 2008, the oily phase consisted of isopropyl palmitate (IPP); in case of $0 / \mathrm{W}$ emulsion the concentration used was $15 \%$ and water $39 \%$, while vice versa in case of $\mathrm{W} / 0$ emulsion. In all cases, the model drug was used in $1 \%[71,72]$. 
In both studies, the transdermal fluxes through human epidermis (heat-separated) were investigated in vitro using customized Franz diffusion cells. Similar results were obtained; where the O/W MEs resulted in the highest flux of the hydrophobic model drugs in comparison with to the other formulations, providing the highest skin permeation enhancement. The permeation measurements revealed that the type of ME was an essential factor for transdermal drug delivery. Furthermore, the MWT of the model drugs had an inverse effect on the skin permeation [71,72]. In addition, the interaction between the drug and the surfactant had a strong effect on the skin permeation of drug from MEs [72].

Consequently, according to the results of the two former studies, transdermal fluxes values that are shown in Table 1, revealed that O/W MEs of the hydrophobic base form of the investigated model drugs improved the permeation through the skin in a much more significant way compared to the other formulated preparations. In addition, the Brij97-based MEs showed lower fluxes than the AOTbased MEs systems (highest fluxes reached $21.45 \mu \mathrm{g} / \mathrm{h} / \mathrm{cm}^{2}$ and $73.05 \mu \mathrm{g} / \mathrm{h} / \mathrm{cm}^{2}$, respectively). Furhermore, the lidocaine base that was diffused from AOT-based MEs through excised skin showed the uppermost flux $\left(73.05 \mu \mathrm{g} / \mathrm{h} / \mathrm{cm}^{2}\right)$ as compared to the tetracaine group $\left(2.52 \mu \mathrm{g} / \mathrm{h} / \mathrm{cm}^{2}\right)$ and the dibucaine group $\left(3.40 \mu \mathrm{g} / \mathrm{h} / \mathrm{cm}^{2}\right)$ due to its smallest MWT. This is pertaining to the higher drug mobility or diffusion coefficient and subsequently higher permeation through the intact epidermis of low MWT moieties. There was a slight difference in fluxes between the tetracaine group and dibucaine group despite that tetracaine group has lesser MWT than the dibucaine group. This may be interpreted with another factor that there might be an interaction inbetween tetracaine and AOT moieties [71,72].

Furthermore, in 2008, research work was conducted on hydrocortisone acetate (HCA), which is a poorly water-soluble drug, aiming for its topical delivery. Four formulations containing HCA were prepared, comprising two aqueous based systems and another two hydrophobic based systems. Hydrophobic ME was prepared by three emulsifiers (Transcutol, Labrafil, and Labrasol), Plurol Oleique, and water. Another ME was prepared, a hydrophilic one, it was composed of Transcutol, liquid paraffin, and propylene glycol. Furthermore, an aqueous gel and an ointment were prepared. The animal membrane was used for testing the release and permeation of HCA by means of a Franz cell. Both the hydrophobic and the hydrophilic MEs promoted the permeation, in comparison to the gel and the ointment formulations. The hydrophobic ME showed the highest solubility and flux $(2370 \mu \mathrm{g} / \mathrm{ml}$ and $133 \mu \mathrm{g} / \mathrm{cm}^{2} . \mathrm{h}$ ) of the drug, as it contains about $40 \%$ Transcutol, which is known for its potent permeation enhancing ability. On the other hand, the ointment formulation provided the lowest solubility and flux $\left(562 \mu \mathrm{g} / \mathrm{ml}\right.$ and $0.4 \mu \mathrm{g} / \mathrm{cm}^{2}$.h). It was also mentioned that in the case of hydrophilic ME it required a high content of surfactants which may lead to an allergic reaction. According to the previously mentioned experimental results, it was concluded that gels and ointments can be appropriate when it is advantageous to minimize the absorption of topically applied HCA with the purpose of restricting the drug to the diseased area and the prevention side effects in case of the systemic presence of HCA [73].

In 2010, the main purpose of research was to attempt to develop and optimize ME-based transdermal therapeutic system of lacidipine (LCDP), which have low aqueous solubility and poor bioavailable drug. The optimization of the ME was performed by means of a three-factor and three-level "Box-Behnken" design. The nominated independent variables were the surfactants mixture $\left(\mathrm{S}_{\text {mix }}\right)$ (Labrasol ${ }^{\circledast}$ and Tween 80), the oily phase (IPM) and water, while the responses were three dependent variables; the cumulative amount permeated across excised rat skin in $24 \mathrm{~h}$ (Q24; Y1), together with the flux (Y2) and the lag time (Y3). Unlike what is commonly known in literature that increasing the surfactants amounts usually lead to increase in the amount of drug permeated; here, it was observed that on increasing the amount of surfactant mixture, the flux and amount permeated of
LCDP decreased, in addition, to increase in the lag period. Not only the increase of the surfactant mixture amount leads to these observations but also the increase in the oil content showed the same effect. This may be attributable to the high affinity of LCDP to the surfactants and the oily phase, also due to the decreased thermodynamic activity of LCDP in $\mathrm{ME}$ at higher surfactant concentrations. Accordingly, a gel was prepared from the optimized ME formulation (ME-OPT) consisted of 6.5\% IPM, $11.4 \%$ of the SAA and coSAA mixture (Tween 80 and Labrasol) as well as $82 \%$ water together with the gelling agent; hydroxypropyl methyl cellulose (K 4M) 4\% (w/v). The gel formulation usually leads to an increase in viscosity and thus decreases in the amount permeated and flux. Nevertheless, this formulation showed a flux of $43.7 \mu \mathrm{g} / \mathrm{cm}^{2} / \mathrm{h}$, which could reach the target flux $\left(12.16 \mu \mathrm{g} / \mathrm{cm}^{2} / \mathrm{h}\right)$. Bioavailability (BAV) studies were also performed in rabbits showing that the BAV of the ME gel after transdermal administration was improved by around 3.5 multiples, which was statistically significant $(\mathrm{p}<0.05)$ compared to the oral suspension. The results established that the formulation was none irritating and did not cause any erythema on transdermal administration. Good ex vivo-in vivo correlation was obtained with correlation coefficients of 0.938 and 0.993 during lag and permeation phases, respectively. To this point, the ME therapeutic system aimed for transdermal delivery of LCDP was prepared and optimized and could provide effective treatment in the management of hypertension [74].

Furthermore, in the same year (2010), a study was conducted with the objective of developing ME formula intended for transdermal delivery of the hydrophobic drug testosterone which is used in androgen replacement therapy. The main aim of the study was to include large quantities of water and oil in ME; the total monophasic area (water and oil) was employed as a solubilization parameter (AT). Achieving the highest (AT), the maximum amount of solubilized water (Wm), and the minimum amount of surfactant $(\mathrm{Sm})$ were the main target. Three surfactants were studied Tween20, Tween 40 , and Tween80. Tween20 (C-12) has the shortest chain length along with the highest hydrophilicity (HLB 16.7), showed the highest capacity for water incorporation. Although the ability to incorporated water is a function of Tween chain length, the Tween 80 showed higher water capacity than Tween 40; this is due to the presence of unsaturation at C-9. ME formulations were prepared using different ratios of oily phase (oleic acid), surfactant mixture containing Tween20 and Transcutol ${ }^{\circledR}$, and water. On MEs characterization, the conductivity measurements revealed the point at which the ME went through the conversion from $\mathrm{W} / \mathrm{O}$ to bicontinuous phase. The delivery from different formulations of testosterone was evaluated across excised skin (porcine) ex vivo utilizing Franz diffusion cells. Accordingly, the study concluded that the drug was primarily found in the oily domains of the MEs. In addition, the delivery of testosterone across the skin was successful from the MEs, with the uppermost flux reaching $\left(4.6 \mu \mathrm{g} / \mathrm{cm}^{-2} / \mathrm{h}\right)$, this was achieved by the formula that contained $3 \%(\mathrm{w} / \mathrm{v})$ of testosterone and was composed of $16 \%$ oleic acid, $32 \%$ Transcutol $^{\circledR}, 32 \%$ Tween 20 , and $20 \%$ water $(\mathrm{w} / \mathrm{w})$. The increase in water content leads to an increase in the flux of testosterone; this is due to high thermodynamic activity of testosterone with better skin hydration. Furthermore, oleic acid is known for its great penetration enhancing ability; thus, the decrease of oleic acid below $16 \%$ leads to a decrease in the flux of testosterone. In a nutshell, the MEs offer potentially worthy vehicles for the transdermal delivery of testosterone [21].

In 2011, ME systems were prepared for the purpose of investigating them as transdermal delivery vehicles for curcumin. The ME systems were composed of terpenes as oily phase, surfactant Polysorbate 80, cosurfactants (ethanol, isopropanol, and propylene glycol), and water. Curcumin is currently used as an anti-inflammatory, an anticancer, an antioxidant, a wound healing, and an antimicrobial agent. Pseudoternary phase diagrams of different types of terpenes; three to be exact, known as 1,8-cineole, limonene, and $\alpha$-terpineol at a fixed SAA-coSAA ratio (1:1) were made. The transdermal delivery efficiency and retain the ability of the skin for curcumin were evaluated through excised neonate pig skin utilizing a Franz diffusion cell. Significant effects on the 


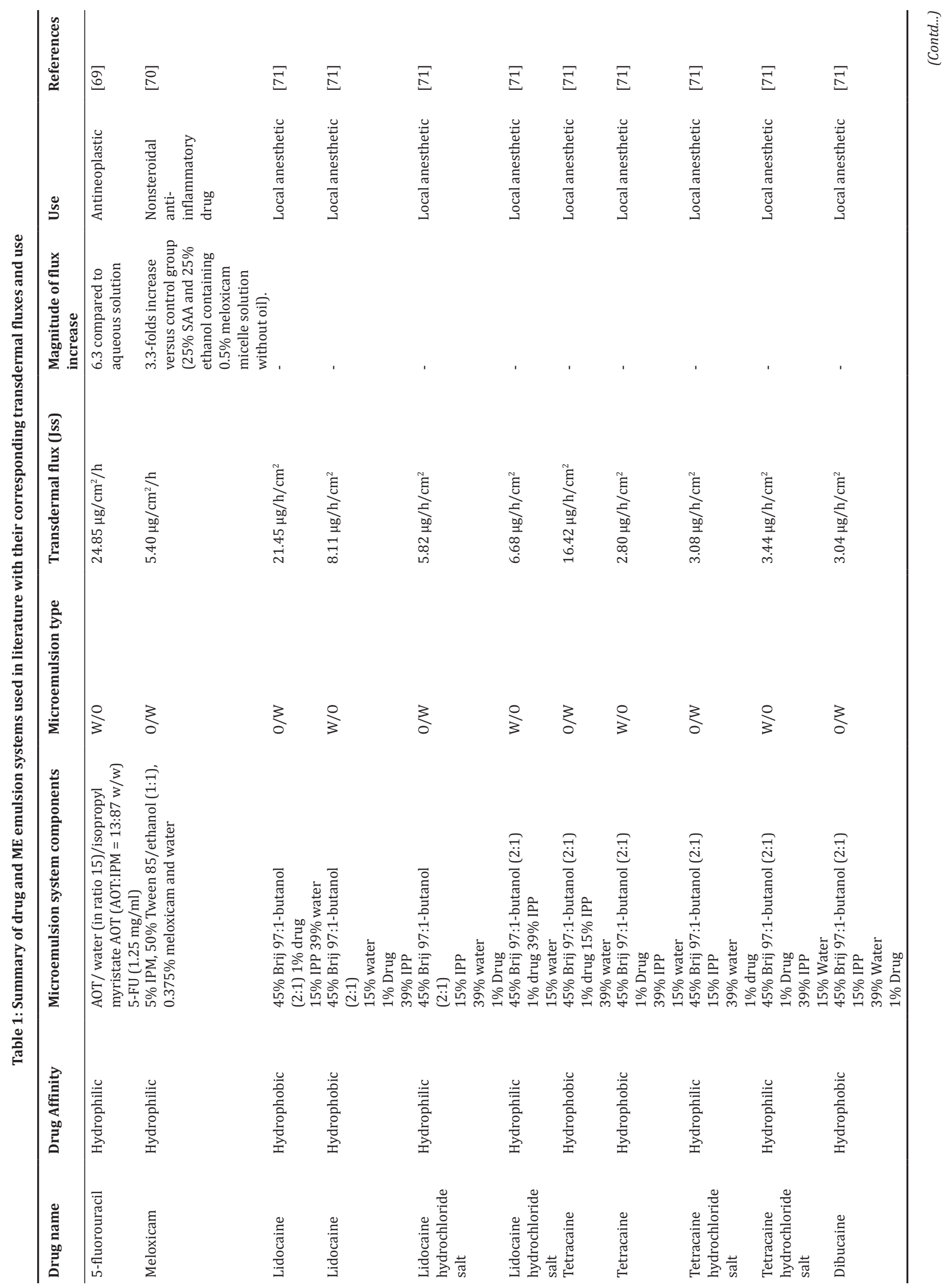




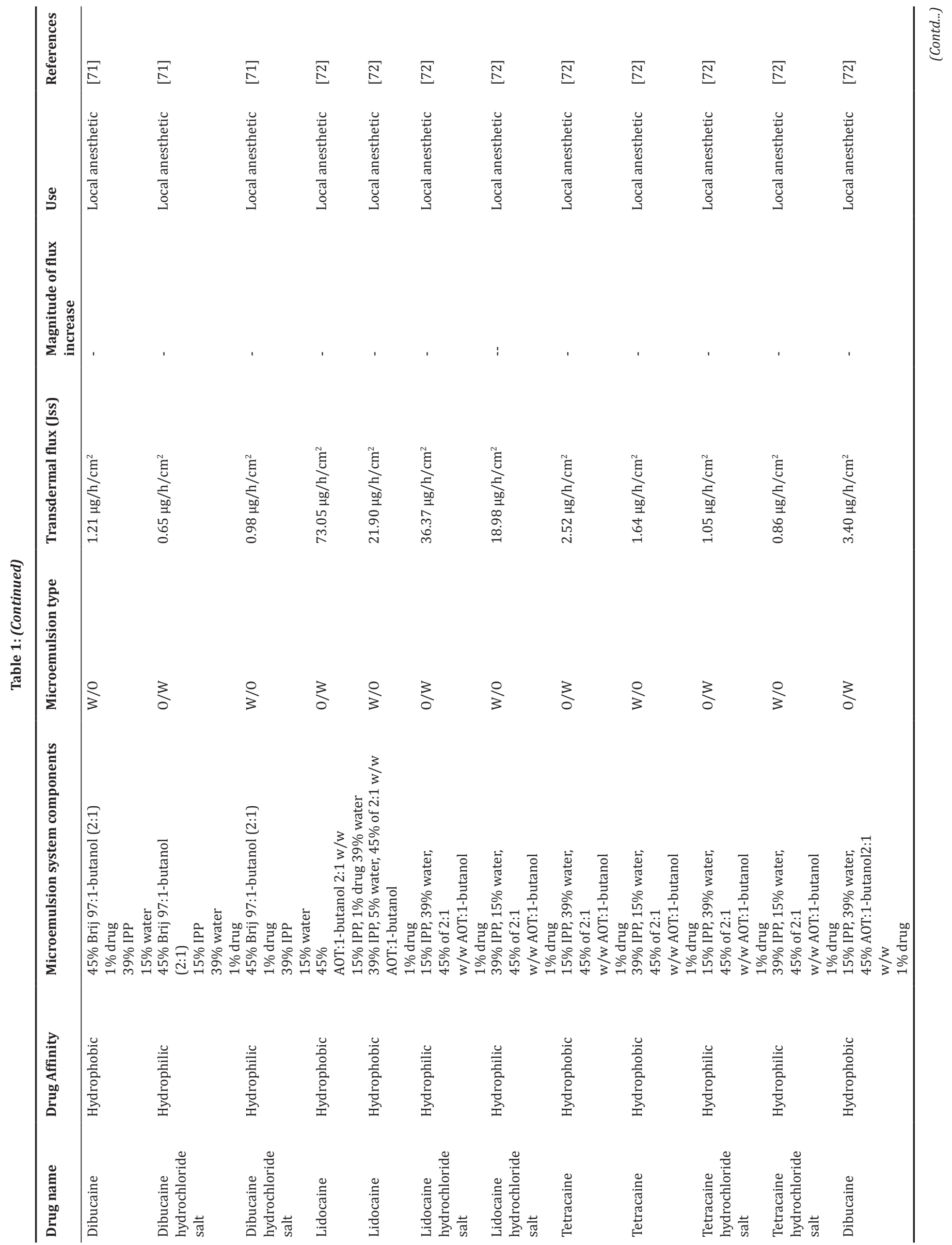




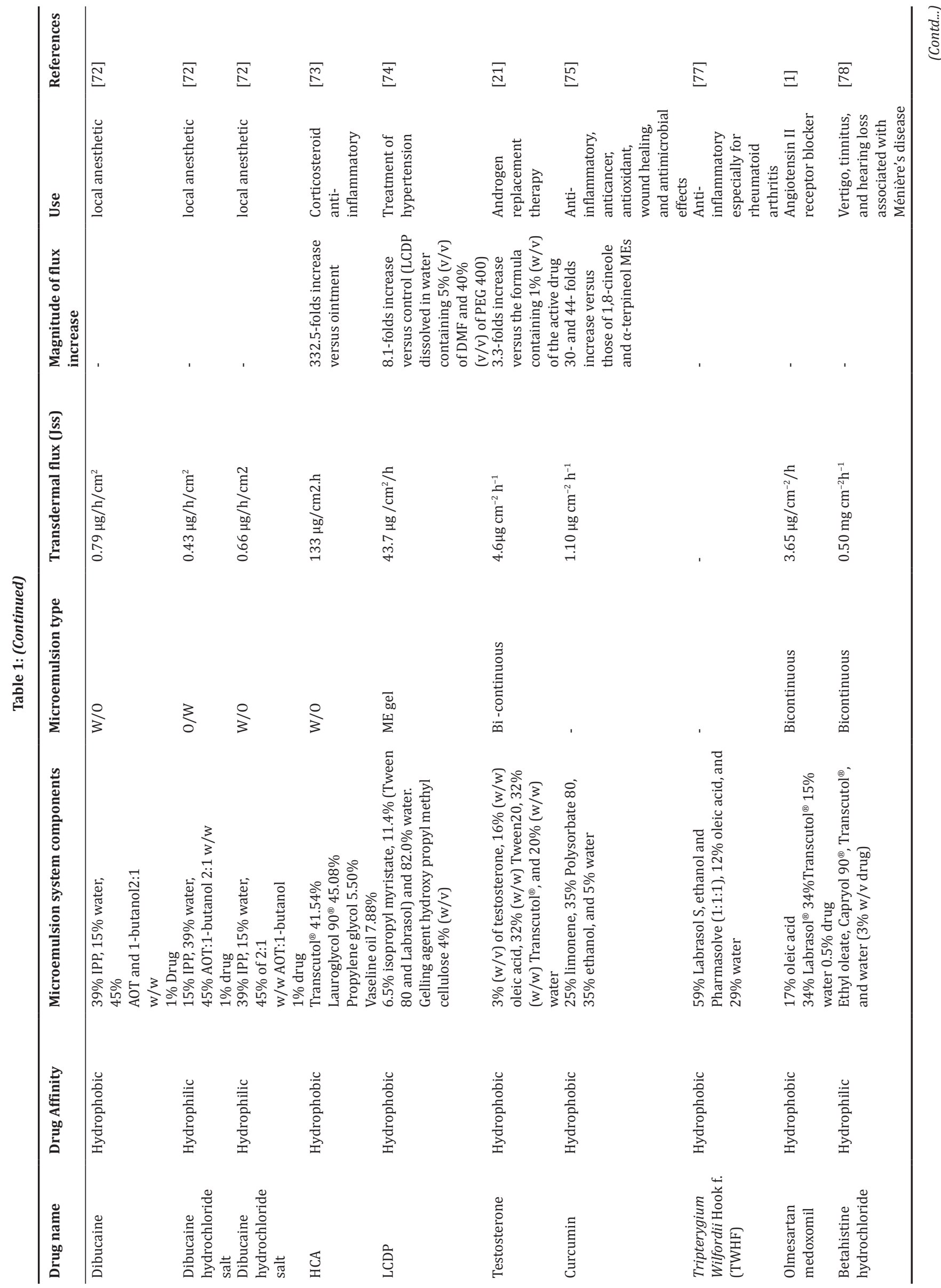




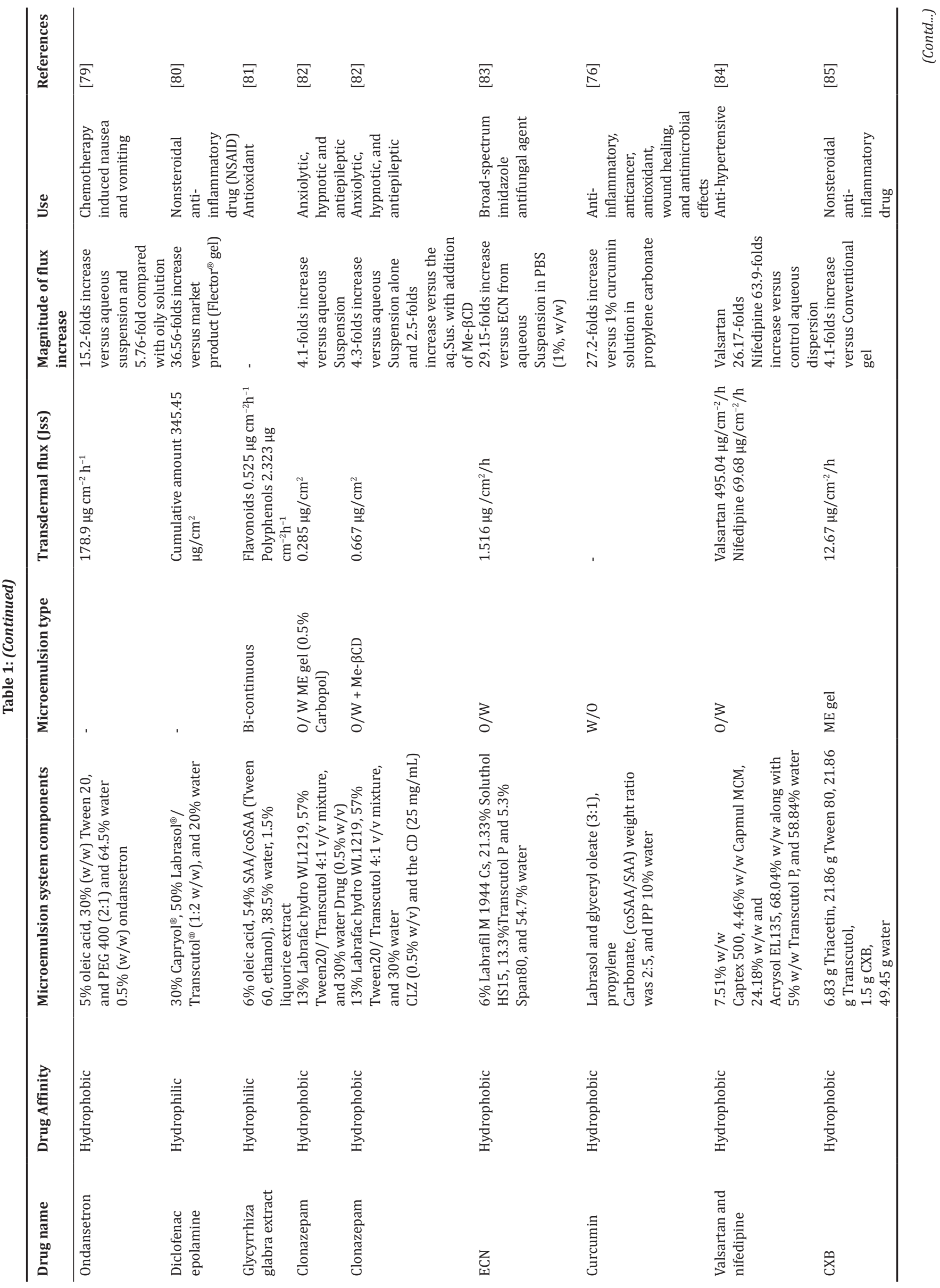




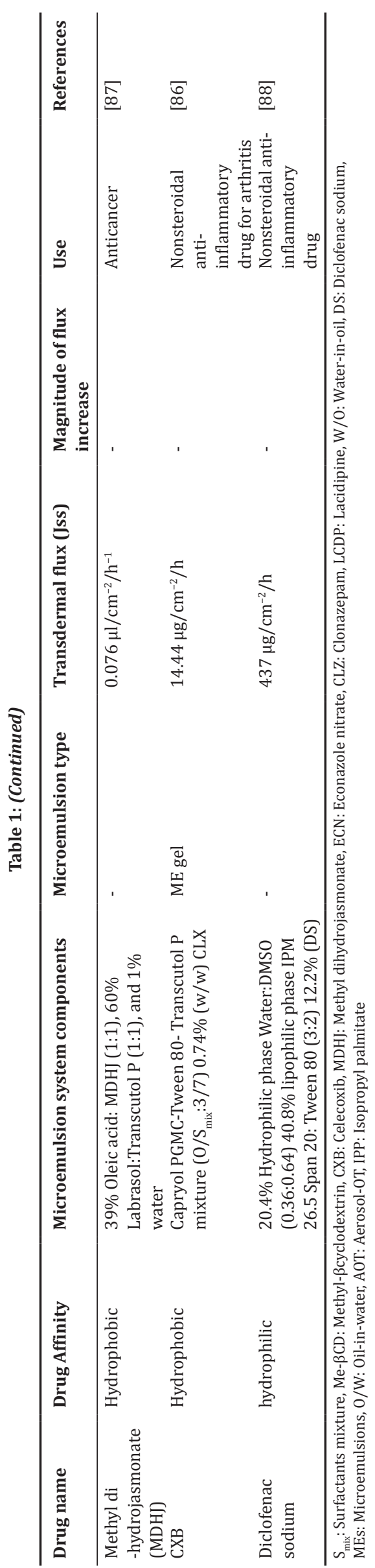

skin permeation rates were observed. Various short chain cosurfactants were considered. The results of the study revealed that the curcumin flux of the limonene ME using ethanol as the coSAA was 41- and 19fold higher compared with those using isopropanol (IP) and propylene glycol (PG), respectively. The reason behind this is that increasing the chain length lead to a decrease in the transdermal flux, while increasing the amount of hydroxyl groups present in the chain leads to increase in flux as in case of PG and IP. The ME system containing 25\% limonene, $35 \%$ Polysorbate $80,35 \%$ ethanol, and $5 \%$ water with $0.4 \%$ curcumin, reached a flux of $1.10 \mu \mathrm{g} / \mathrm{cm}^{-2} / \mathrm{h}$ as well as a cumulative amount of $30 \mu \mathrm{g} / \mathrm{cm}^{-2}$ permeated over $24 \mathrm{~h}$. These results indicated that the limonene ME system showed enhanced transdermal curcumin delivery in comparison with 1,8-cineole, and $\alpha$-terpineol through lowering the diffusional barrier of the SC and dropping the viscosity. The decrease of the affinity of curcumin to the oily phase in ME was one of the reasons for the increased transdermal flux. Thereby, the study introduced an encouraging tool for the delivery of curcumin transdermally [75].

It is worth to note that the use of MEs in the transdermal delivery of curcumin continued in 2015 where different ME systems were investigated. The prepared W/O ME was composed of Labrasol and glyceryl oleate as surfactants $3: 1$, propylene carbonate as cosurfactant, the coSAA/SAA weight ratio was 2:5. IPP was used as the oily phase and water as the aqueous phase. The skin permeability of curcumin from ME formulations, which contained different aqueous phase content $5 \%, 10 \%$, and $20 \%$ of water, together with curcumin concentration of $1 \%$ was evaluated ex vivo by means of excised rat skin. It was observed in this study that the formulation with $10 \%$ water gave a permeability coefficient for curcumin two-folds higher than those with $5 \%$ and $20 \%$ water $\left(\mathrm{p}=0.116 \times 10^{-3}, 0.043 \times 10^{-3}\right.$, and $0.047 \times 10^{-3} \mathrm{~cm} / \mathrm{h}$, respectively). A reasonable explanation for this phenomenon may be the reduction of both droplet sizes as the aqueous phase ratio reduced from $20 \%$ to $5 \%$. Despite that $5 \%$ had smaller droplet size than that of the $10 \%$, it showed lower permeation. This was explained by the effect of droplets' concentration in the ME, as it is believed that the $\mathrm{W} / \mathrm{O}$ formulation with $5 \%$ water contains a smaller number of droplets per unit volume than the formulation with $10 \%$ water due to Bingham plastic behavior of the later. The cumulative amount permeated over $24 \mathrm{~h}$ was $18.78 \mu \mathrm{g} /$ $\mathrm{cm}^{-2}$ from ME containing $10 \%$ water and $1 \%$ curcumin, while using $3 \%$ curcumin the amount permeated reached $48.38 \mu \mathrm{g} / \mathrm{cm}^{-2}$. It was also observed, that there is a linear correlation that with the upsurge of curcumin concentration in the ME there was a reduction in the size of the droplet. The study concluded that the suggested delivery system was advantageous in the delivery of curcumin [76].

By comparing the two studies, it was observed that despite the difference in the loaded amount of curcumin $0.4 \%$ and $1 \%$ in 2011 and 2015 , respectively, the cumulative amount permeated from the formula proposed by Liu in 2011 was higher than that of Sintov in 2015 by 1.6fold.

In 2012, a study was conducted aiming to produce a ME system for transdermal drug delivery of a Chinese herb known as Tripterygium wilfordii Hook f. (TWHF), which is used as anti-inflammatory especially for rheumatoid arthritis in attempt to solve its associated male reproductive toxicity problem. The central composite design (CCD) and response surface methodology were used to optimize the formulation. The optimum components percentages were as follows: $12 \%$ oleic acid, $19.7 \%$ ethanol, and 19.7\% Pharmasolve ${ }^{\circledR}, 19.7 \%$ Labrasol S, and $29 \%$ water. The free TWHF showed poor permeation through excised mice skin, while the developed ME system for TWHF showed an enhanced permeation. The cumulative amount permeated from the ME formulation was $35.87 \mathrm{mg} / \mathrm{ml}$ for $24 \mathrm{~h}$, higher than that of the blank group $(25.13 \mathrm{mg} / \mathrm{ml})$. TWHF ME exhibited a significant effect on the inhibition of adjuvant-induced arthritis and also demonstrated a favorable effect in conquering the inflammation with the prolonged usage. Different pharmacodynamics parameters indicated that TWHF ME has the ability to reduce the associated male reproductive toxicity in addition to hepatotoxicity in rats. It was concluded that the developed 
transdermal drug delivery ME system could be a suitable delivery system for TWHF [77].

In the same year (2012), Hathout and ElShafeey [1] developed a successful ME delivery system for the purpose of transdermal permeation of olmesartan medoxomil; an angiotensin II receptor blocker, which is a hydrophobic drug. Different formulas were tested they all comprised an oily phase of oleic acid, surfactant mixture (1:1) of Labrasol ${ }^{\circledR}$ and Transcutol ${ }^{\circledR}$, and water. The percentages of water varied from $5 \%$ to $28 \%$, for oleic acid from $19 \%$ to $14.4 \%$, and for the $S_{\text {mix }}$ from $76 \%$ to $57.6 \%$. The formulation is reaching highest permeation due to balanced effect between water content (hydration effect) and the presence of permeation enhancers either the $S_{\text {mix }}$ or oleic acid was selected as the best formulation. The ME containing $17 \%$ oleic acid, 34\% Labrasol ${ }^{\circledR}, 34 \%$ Transcutol $^{\circledR}, 15 \%$ Water, and $0.5 \%$ olmesartan medoxomil was transported transdermally with fluxes reaching $3.65 \mu \mathrm{g} / \mathrm{cm}^{-2} / \mathrm{h}$. Furthermore, better BAV results were attained in comparison with the commercial oral tablets, accompanied with a sustained behavior.

In 2013, the transdermal delivery of a hydrophilic drug; betahistine hydrochloride was investigated. It acts as an active histamine analog that is used to reduce and relieve the symptoms of vertigo, tinnitus, and hearing loss associated with Ménière's disease. Betahistine hydrochloride was added in various ethyl oleate $(10 \%, 15 \%$, and $40 \%)$, Capryol $90^{\circledR}$ (35\% and 27.5\%), Transcutol ${ }^{\circledR}$ (35\% and 27.5\%), and water $(20 \%, 15 \%$, and $5 \%)$ ME formulations. The pseudoplastic flow that is usually desirable for transdermal delivery was verified for the studied MEs to ensure stability at the shelf on the one hand and the ease pouring from containers during administration on the other hand. A reasonable and bicontinuous ME formulation containing 3\% w/v betahistine hydrochloride was selected and showed the highest permeation flux $\left(0.50 \mathrm{mg} \mathrm{cm}^{-2} \mathrm{~h}^{-1}\right)$. The formulation had equal ratios of water and ethyl oleate (15\%). A high percentage of water decreases the amount of penetration enhancer ethyl oleate, and vice versa causes lower skin hydration. To elucidate the high permeation fluxes obtained, the effect of the investigated MEs on the skin electrical resistance was used. The formula with $40 \%$ ethyl oleate showed almost the same effect on decreasing the skin resistance as that with only $15 \%$ ethyl oleate this was explained by the presence of bicontinuous dynamic structure of the later which have the prominent penetrating ability and disrupting effects on the skin structural design. To reveal the penetration pathways and to confirm, the permeation enhancement confocal laser scanning microscopy was used. The results demonstrated that the permeation of the ME formula occurred through the three pathways paracellular, intercellular, and appendageal. The results recommended that prepared ME could be used as an alternative delivery means for betahistine hydrochloride [78].

In the same year (2013), the chief goal of research work was to formulate a ME for transdermal delivery of ondansetron for the treatment of the chemotherapy-induced nausea and vomiting. The selection of the oily phase was based on the solubility of ondansetron in different oils, while the selection of surfactant was based on the solubility of the selected oil (oleic acid) in them. Tween 20 surfactant was found to be most suitable out of all tested SAA (Labrasol ${ }^{\circledR}$, Tween 20, Tween 60, Tween 80, and Acconan CC6) and was used to select the appropriate cosurfactant through evaluating the cosurfactant's emulsification efficiency. PEG 400 was found to have the largest ME domain in comparison with Transcutol ${ }^{\circledast}$, Span 80, and Span 20. Furthermore, the cosurfactant and surfactant were combined in different mass ratios, the effect of the $S_{\text {mix }}$ on the ME formation and its permeation was investigated using rat skin. The formulation consisting of $0.5 \%(\mathrm{w} / \mathrm{w})$ of ondansetron, $30 \%$ $(\mathrm{w} / \mathrm{w}) \mathrm{S}_{\text {mix }}(2: 1$, Tween 20 , and PEG 400), $5 \%(\mathrm{w} / \mathrm{w})$ of oleic acid, and $64.5 \%(\mathrm{w} / \mathrm{w})$ of distilled water presented the highest permeability with flux of $178.9 \mu \mathrm{g} / \mathrm{cm}^{-2} / \mathrm{h}$. Usually, the increase in $\mathrm{S}_{\text {mix }}$ percentages leads to increase in the permeation due to its penetration enhancing ability this was observed while increasing the $S_{\text {mix }}$ percentage from $15 \%$ to $30 \%$. However, further increase in the percentage of $S_{\text {mix }}$ lead to decrease in permeation, this may be due to the detail that at high SAA concentration the affinity of the drug to the vehicle is increased and by that decrease the thermodynamic activity of the drug in the ME. A ME gel (OMG) was prepared from the bet ME formulation using of Carbopol 934 in concentration $0.75 \%$. To predict the efficacy of the chosen ME formulation, pharmacokinetic studies were made, comparing the ondansetron conventional gel (OCG) with oral marketed syrup (ONDANZ). The results showed that the absorption of ondansetron from OMG is 6.03 folds higher in BAV in comparison with ONDANZ, while 9.66 folds higher in BAV than the OCG gel [79].

Moreover, in 2013, a ME system together with poloxamer ME-based gel (PMBG) containing diclofenac epolamine (DE) were prepared and optimized. The aim of developing the systems was to improve DE transport into the skin and to form a depot for it in the skin to ensure its sustained transdermal delivery. A mixture experimental design (D-optimal) was employed to reach the ME system that comprises best drug solubility in addition to the highest amount of oil and with the smallest globule size. The optimized ME formulation composed of $50 \%$ $\mathrm{S}_{\text {mix }}$ (a blend of Labrasol $^{\circledR}:$ Transcutol $^{\circledR}, 1: 2 \mathrm{w} / \mathrm{w}$ ), 30\% Capryol $^{\circledR}$, and $20 \%$ water. The optimum ME and PMBG formulations were assessed by various parameters including ex vivo permeation through rat skin. The highest cumulative amount of DE permeated through $8 \mathrm{~h}$ was $345.45 \mu \mathrm{g} / \mathrm{cm}^{2}$, this was achieved by the optimized ME formula, contrary to PMBG and Flector ${ }^{\circledR}$ gel. In addition, the in vivo anti-inflammatory effectiveness was evaluated using rat paw edema. The effect was also evaluated $12 \mathrm{~h}$ after the withdrawal of the ME, and it was found to be persistent, which verified the development of the depot action. As a result of the high quantity of drug present in oil globules which could effortlessly pass through the lipids of SC, the ME system for DE showed high permeation results. Furthermore, as a consequence of the presence of the high amount of water in PMBG (about 75\%) and with a high quantity of DE interacting with poloxamer micelles in the aqueous phase, the transport rate through the skin was lowered. The study recommended that the prepared system would have an encouraging role in the transdermal delivery of DE with sustained action for the aim of treating soft tissue injuries [80].

In 2014, another study was conducted with the purpose of highlighting the significance of formulation on taking full advantage of the therapeutic usefulness of biologically active phytochemicals. The aim of the research work was to formulate Glycyrrhiza glabra root and rhizome aqueous ethanolic extract in a ME delivery system proposed for the transdermal delivery of the integrated antioxidant actives, flavonoids, and polyphenols. Three ME systems were prepared. The oily phase of all three consisted of oleic acid but in different percentages $13.5 \%$, $23.14 \%$, and 6\%). The Tween 60 and ethanol were used as surfactants and cosurfactants, respectively, in multiple SAA/coSAA ratios 1:1, 2:1, and $3: 1$, and at a constant weight percentage of the mixture $54 \%$. The obtained results revealed that the bicontinuous ME system consisting of $6 \%$ oleic acid, $54 \%$ SAA/coSAA (Tween 60 and ethanol [3:1]), 38.5\% water, $1.5 \%$ liquorice extract, has the most favorable characteristics concerning the drug content (flavonoids and polyphenols), pH, viscosity, zeta potential, high stability particle size, and polydispersity index. Furthermore, the selected ME formulation attained high permeation capability mutually for the flavonoid and the polyphenol contents of the integrated liquorice extract (flux of $0.525-0.063 \mu \mathrm{g} / \mathrm{cm}^{-2} / \mathrm{h}$ for flavonoids and $2.323-0.043 \mu \mathrm{g} / \mathrm{cm}^{-2} / \mathrm{h}$ for polyphenols). This may be as a result of the high water content in this formula compared to the other formulas. The water content caused hydration for the proteins in the SC and triggered disordering of the lipid layers. Thus, the formulation of liquorice extract in a ME may possibly be efficiently employed as a costeffective non-invasive transdermal formulation with a vastly potent antioxidant potentiality, apart from the difficulties faced in oral delivery and the inconvenience to patients met in parenteral delivery [81].

Another study was performed in 2014, where the transdermal administration of clonazepam (CLZ), which is a benzodiazepine, was investigated. One of the difficulties faced in formulating CLZ is its poor 
aqueous solubility. The main purpose of the study was to overcome the shortcomings of its oral administration. Nanocarrier formulations were developed, to be more specific two types were prepared; ultradeformable liposomes and MEs. Gels comprising liposomal or ME formulations have been prepared and characterized for the aim of transdermal delivery of CLZ. Methyl- $\beta$ cyclodextrin (Me- $\beta C D$ ) addition to the formulations was investigated, as it has the high solubilizing capability for CLZ and it also attains some positive effects on transdermal drug delivery. CLZ permeation from the formulations was evaluated using artificial lipophilic membranes. Compared to those from an aqueous drug suspension, with or without Me- $\beta C D$, gels containing $0 / W$ MEs (57\% Tween 20/Transcutol 4:1 v/v mixture, 13\% Labrafac Hydro WL1219, 30\% water, and 0.5\% Carbopol), were significantly higher in effectiveness in improving the drug permeation rate, in comparison with the liposomal formulations $(\mathrm{p}<0.05)$. However, no significant vicissitudes were detected in the presence of Me- $\beta C D$. In contrast, the addition of Me- $\beta C D$ showed significant effect on permeation when performed the study through excised rabbit ear as a skin membrane, exhibiting more than $100 \%$ upsurge in the CLZ permeability. The fluxes of ME formulation with Me- $\beta C D$ are reached $0.285-0.026 \mu \mathrm{g} / \mathrm{cm}^{2}$ and for ME formulation without Me- $\beta C D$ 0.667-0.063 $\mu \mathrm{g} / \mathrm{cm}^{2}$. Based on the previous results, the enhancing of penetration effect by Me- $\beta C D$ has been proven. This is probably due to its complexing capability toward the lipids in the skin, possibly enhanced by the presence of Transcutol, which has an aptitude for interacting with the components found in the skin barrier [82].

Furthermore, in 2014, a study using MEs as an alternate transferor for the percutaneous delivery of the hydrophobic molecule econazole nitrate (ECN) was performed. The selection of oils, surfactants, and cosurfactants was based on the solubility of ECN in them. Multiple oils, surfactants, and cosurfactants were screened. For the oily phase Labrafil M 1944Cs, ethyl oleate, IPP, IPM, and WM-GTCC were used, as for Cremophor EL, Solutol HS15, and Tween 80 were employed as surfactants while PEG400 and Transcutol P as cosurfactants. An innovative O/W ME system was prepared, which was made up of Labrafil M1944Cs forming the oily phase, Solutol HS15 together with Span 80 as surfactants, in addition to, Transcutol $\mathrm{P}$ as cosurfactant and water for the aqueous phase. An in vitro permeation investigation was conducted to evaluate the prepared formulation. The results revealed that the ME enhanced the ECN retention in the skin accompanied by better permeation through the skin with fluxes reaching $1.516 \mu \mathrm{g} / \mathrm{cm}^{2} / \mathrm{h}$. Furthermore, a ME pretreated skin was used for the ECN permeation testing. The results of this combined with the achieved permeation results of ECN loaded ME revealed that ME is not only drug carriers but also acts as an exceptional penetration enhancer. Transmission electron microscopy and attenuated total reflectance Fourier transform infrared investigations indicated that the ME overcame the SC shield through the alteration of the SC microstructure and molecular vibrations. In general, the outcomes supported the conclusion that the ME is a promising system for ECN percutaneous delivery [83].

In 2016, the goal of research work was to optimize the proportion of a number of components for formulating oil-in-water ME formulation meant for the simultaneous transdermal delivery of two poorly soluble antihypertensive drugs valsartan and nifedipine. The selection of the oily phase was based on the solubility of both drugs in different oils, while the selection of surfactant was based on the solubility of the selected oil in them. Acrysol K150 surfactant was found to be most suitable out of all tested SAA (Tween 20, Tween 80, Acrysol EL 135, Acrysol K 140, and Acrysol K150) and was used to select the appropriate cosurfactant through evaluating the cosurfactant's emulsification efficiency. A surface response methodology, namely the Box-Behnken design, was utilized to evaluate the influence of two oils; Captex 500 - x1 and Capmul MCM - x2 and a surfactant: Acrysol EL135 - x3 on three responses: $\mathrm{y} 1$ (particle size), y2 (solubility of valsartan), and y3 (solubility of nifedipine). The design revealed an inverse correlation between the particle size and the concentration of Capmul MCM and Acrysol EL 135. The optimum composition consisted of 7.51\% w/w Captex 500, 4.46\% w/w Capmul
MCM, 24.18\% w/w and Acrysol EL135, 68.04\% w/w along with $5 \% \mathrm{w} / \mathrm{w}$ Transcutol $\mathrm{P}$ and $58.84 \%$. The obtained ME exhibited a globule size of $5.32 \mathrm{~nm}$ and optimum solubility of valsartan and nifedipine of $21.31 \mathrm{mg} / \mathrm{g}$ and $6.22 \mathrm{mg} / \mathrm{g}$, respectively. Therefore, the aforementioned investigated design could be used for developing a ME system containing two drugs with low particle size [84].

Furthermore, in 2016, an investigation was performed on Celecoxib (CXB) a poorly aqueous soluble sulfonamide and a NSAID drug. The aim of the study was to find out a suitable ME preparation of the drug and optimizing it using an orthogonal experimental design and responses surface methodology. Hence, the ME formulation of CXB that was selected based on solubilization and BAV. The solubility of CXB in various oils was screened such as castor oil, IPM, triacetin, ethyl oleate, and olive oil; surfactants such as Labrasol, Tween 40, Tween 80, and Labrafil, and cosurfactants including ethanol, propylene glycol, Transcutol-P, and PEG 400 were determined. CCD was used to optimize the ratio of selected $\mathrm{S}_{\text {mix }}$ oil, and water based on the responses cumulative amount releases and flux. The best ME was prepared with triacetin (6.83\%), Tween 80 (21.86\%), and Transcutol-P (21.86\%) to achieve the optimum qualities of globule size and drug loading. To enhance the viscosity and retention in the skin, 1\% Carbopol 934 was added to form the CXB ME-based gel. Its ex vivo drug permeation and the in vivo pharmacokinetics were investigated. Regarding the $e x$ vivo permeation study in mice, the final formulation showed higher permeation $\left(12.67 \mu \mathrm{g} / \mathrm{cm}^{2} \mathrm{~h}\right)$ as compared to a conventional gel preparation and the transdermal ability was greatly improved based on smaller globule size and high drug loading of the ME system. The in vivo pharmacokinetic study in rabbits revealed enhanced BAV compared to the marketed product Celebrex ${ }^{\circledR}$. Therefore, the results of this study have indicated that the CXB ME based gel could be a promising formulation in drug delivery leading to better results compared to the conventional dosage forms [85].

Similarly, in 2017, the aim of research work was to incorporate CXB in a ME-based hydrogel containing for transdermal delivery. Different components were screened Oil: Capryol PGMC, Capmul MCM, and Triacetin; Surfactant: Tween 80 and Labrasol; and Cosurfactant: Transcutol $\mathrm{P}$ and the selection were founded on the solubility of CLX. Then, the designated components were employed to construct pseudo-ternary phase diagram. Based on the highest ME region in the pseudo-ternary phase diagram, Capryol PGMC as oil, Tween 80, and Transcutol $\mathrm{P}$ as $\mathrm{S}_{\text {mix }}$ and water as aqueous phase were selected to form the ME system. The increase in the $0 / S_{\text {mix }}$ ratio from $1 / 9$ to $3 / 7$ in the ME leads to better in vitro skin permeation and a decrease in lag time through excised hairless mouse skin, with flux reaching 8.86 and $14.44 \mu \mathrm{g} / \mathrm{cm}^{2} / \mathrm{h}$ and a lag time of 9.58 and $3.63 \mathrm{~h}$, respectively. This is attributed to decreasing the amount of $\mathrm{S}_{\text {mix }}$ (at high $0 / \mathrm{S}_{\text {mix }}$ ratio), which lead to increase in the thermodynamic activity of the drug (CLX), as it is soluble in the $\mathrm{S}_{\text {mix }}$ despite being hydrophobic. The elevation of the thermodynamic activity of the drug leads to an increased release and enhanced transfer and permeation of it through the skin. Furthermore, CLXME caused a transition in the alkyl chain present in the SC lipids, which enhanced the permeation. The gel was prepared by the addition of $0.5 \%(w / w)$ Carbopol 974 to the CLXME. The incorporation of ME in gel controlled the release of $\mathrm{CXB}$, indicating enhanced therapeutic properties of CXB against arthritis [86]

By comparing the two studies, we could conclude that Capryol PGMC as an oily phase had a better effect on increasing the permeability of CLX through the skin rather than triacetin. In addition, the combination of Tween 80 and Transcutol $P$ as surfactant and cosurfactant was found to be efficient in enhancing the transdermal delivery of CXB.

Recently, in 2017, MEs were used in research work for the transdermal transport of another phytochemical naming methyl dihydrojasmonate (MDHJ), which has been reported to attain an anticancer effect. However, it has poor water solubility. Multiple combinations of oils for instance Capryol $90^{\circledR}$, oleic acid, Labrafil $\mathrm{M}^{\circledR}$, Labrafac $\mathrm{PG}^{\circledR}$, 
Labrafac $\mathrm{CC}^{\circledR}$, and IPM in the weight ratio 1:1 with MDHJ; furthermore, Labrasol ${ }^{\circledR}$, Plurol Oleique ${ }^{\circledR}$, Transcutol $\mathrm{P}^{\circledR}$, and Tween $80^{\circledR}$ were used as SAA and/or coSAA, to obtain the best combination based on the largest ME domain formed in the pseudo-ternary phase diagram. Two systems were selected; those comprising oleic acid and Capryol $90^{\circledR}$ in the oily phase and including Transcutol ${ }^{\circledR}$ and Labrasol $^{\circledR}$ as SAA/coSAA. This is due to the beneficial combination of the nonionic surfactants Labrasol $^{\circledR}$ and Transcutol ${ }^{\circledR}$. They are known for their high solubilization power for both oil and water phases. An experimental design naming "Simplex Lattice Mixture Design," was operated to choose ME systems for additional studying through an ex vivo permeation testing using mice skin. Various parameters were evaluated comprising mainly the transdermal fluxes. The ME formulation with oleic acid showed better permeation, as oleic acid is known for its powerful penetration enhancing ability. Furthermore, it was concluded that increasing the concentration of MDHJ in the formula leads to an increase of the transdermal flux. Thereby, the superlative ME formulation reached a flux of $0.07 \mu \mathrm{l} / \mathrm{cm}^{-2} / \mathrm{h}$. The formulation consisted of $39 \%$ oily phase (Oleic acid: $\mathrm{MDHJ}$ in ratio 1:1), $1 \%$ water as the aqueous phase and $60 \%$ Labrasol:Transcutol $\mathrm{P}$ in ratio $1: 1$ as the $\mathrm{S}_{\text {mix }}$. Furthermore, cytotoxicity on MCF-7 a breast cancer cell line together with in vivo studies was carried out and they were followed by histopathological examinations. The results confirmed the effectual transport and the substantial therapeutic effectiveness of the nominated ME formulation compared with placebo formula and pure drug [87].

Newly, diclofenac sodium (DS) was loaded in nonionic MEs for the aim to deliver DS transdermally. Several combinations were used to develop the MEs formulations and evaluated using Franz diffusion cell through shaved rat's skin. The best formulation with the highest flux value reaching $437 \mathrm{mg} / \mathrm{cm}^{-2} / \mathrm{h}$ was with a hydrophilic phase of water:dimethyl sulfoxide (DMSO) $(0.36: 0.64) 20.4 \%$, lipophilic phase of IPM $40.8 \%$, surfactants and cosurfactants Span 20: Tween 80 (3:2) $26.5 \%$, and DS $12.2 \%$; the DS was dissolved in the hydrophilic phase. The main role of DMSO was to act as a penetration enhancer. The combination of Span 20 and Tween 80 leads to a decrease in the viscosity over the formulations with Span 20 only. It is also worth to mention that DMSO and the nonionic surfactants are acceptable pharmaceutical components and used within the recommended amounts by the Food and Drug Administration. A further in vivo study in rates was performed using selected formulations to evaluate its BAV. The in vivo results showed a maximum concentration of 2.43 after 4.14 . Thereby, the study concluded that the developed system may possibly be introduced as a carrier for efficient transdermal delivery of DS [88].

\section{ACKNOWLEDGMENT}

The authors are grateful for Professor Nahed Mortada and Associate Professor Rania Hathout, Pharmaceutics and Industrial Pharmacy Department, Faculty of Pharmacy, Ain Shams University for their scientific mentorship for this work and also thank Professor Khaled El-say, Pharmaceutics and Industrial Pharmacy Department, Faculty of Pharmacy, King Abdulaziz University for his valuable advice. This research did not receive any specific grant from funding agencies in the public, commercial, or not-for-profit sectors.

\section{AUTHORS' CONTRIBUTIONS}

Rania Yehia performed the data collection and manuscript writing. Dalia Attia performed the manuscript organization and revision.

\section{CONFLICTS OF INTEREST}

The authors confirm that this article content has no conflicts of interest.

\section{REFERENCES}

1. Hathout RM, Elshafeey AH. Development and characterization of colloidal soft nano-carriers for transdermal delivery and bioavailability enhancement of an angiotensin II receptor blocker. Eur J Pharm Biopharm 2012;82:230-40
2. Hoar TP, Schulman JH. Transparent water-in-oil dispersions: The oleopathic hydro-micelle. Nature 1943;152:102-3.

3. Barry BW. Novel mechanisms and devices to enable successful transdermal drug delivery. Eur J Pharm Sci 2001;14:101-14.

4. Menon GK. New insights into skin structure: Scratching the surface. Adv Drug Deliv Rev 2002;54:S3-17.

5. Freinkel RK, Woodley DT. The Biology of the Skin. Boca Raton: CRC Press; 2001.

6. Lai-Cheong JE, McGrath JA. Structure and function of skin, hair and nails. Medicine 2009;37:223-6.

7. Matsui T, Amagai M. Dissecting the formation, structure and barrier function of the stratum corneum. Int Immunol 2015;27:269-80.

8. Michaels S, Chandrasekaran SK, Shaw JE. Drug permeation through human skin: Theory and in vitro experimental measurement. AIChE J 1975;21:985-96.

9. FoldvariM. Non-invasive administration of drugs through the skin: Challenges in delivery system design. Pharm Sci Technol Today 2000;3:417-25.

10. Ya-Xian Z, SuetakeT, Tagami H. Number of cell layers of the stratum corneum in normal skin relationship to the anatomical location on the body, age, sex and physical parameters. Arch Dermatol Res 1999;291:555-9

11. Riviere JE, Papich MG. Potential and problems of developing transdermal patches for veterinary applications. Adv Drug Deliv Rev 2001;50:175-203.

12. Verdier-Sevrain S, Bonte F. Skin hydration: A review on its molecular mechanisms. J Cosmet Dermatol 2007;6:75-82.

13. Igarashi $T$, Nishino K, Nayar SK. The appearance of human skin: A survey. Found Trends Comput Graph Vis 2007;3:1-95.

14. Juan EC, Rodríguez-Cruz IM, Domínguez-Delgado CL, DíazTorres R, Revilla-Vázquez AL, Aléncaster NC. Nanocarrier systems for transdermal drug delivery. In: Recent Advances in Novel Drug Carrier Systems. Croatia: Intech Open; 2012.

15. Bolzinger MA, Briancon S, Pelletier J, Chevalier Y. Penetration of drugs through skin, a complex rate-controlling membrane. Curr Opin Colloid Interface Sci 2012;17:156-65.

16. Patzelt A, Lademann J. The increasing importance of the hair follicle route in dermal and transdermal drug delivery. In: Percutaneous Penetration Enhancers Chemical Methods in Penetration Enhancement. Berlin; Heidelberg: Springer; 2015. p. 43-53.

17. Cevc PG, Bachhawat BK. Transdermal immunisation with an integral membrane component, gap junction protein, by means of ultradeformable drug carriers, transfersomes. Vaccine 1998;16:188-95.

18. Kalluri H, Banga AK. Formation and closure of microchannels in skin following microporation. Pharm Res 2011;28:82-94.

19. El-Nabarawi MA, Shaker DS, Attia DA, Hamed SA, In vitro skin permeation and biological evaluation of lornoxicam monolithic transdermal patches. Int J Pharm Pharm Sci 2013;5:242-8.

20. Lopez RF, Seto JE, Blankschtein D, Langer R. Enhancing the transdermal delivery of rigid nanoparticles using the simultaneous application of ultrasound and sodium lauryl sulfate. Biomaterials 2011;32:933-41.

21. Hathout RM, Woodman TJ, Mansour S, Mortada ND, Geneidi AS, Guy RH. Microemulsion formulations for the transdermal delivery of testosterone. Eur J Pharm Sci 2010;40:188-96.

22. Caserta S, Campello S, Tomaiuolo G, Sabetta L, Guido S. Amethodology to study chemotaxis in 3-D collagen gels. AIChE J 2013;59:4025-35.

23. Caserta VS, Russo I, Preziosi V, Ciacci C, Guido S. A novel chemotaxis assay in 3-D collagen gels by time-lapse microscopy. PLoS One 2012; 7:e52251.

24. Moser K, Kriwet K, Kalia YN, Guy RH. Stabilization of supersaturated solutions of a lipophilic drug for dermal delivery. Int J Pharm 2001;224:169-76.

25. Chen X, Gregoire S, Formanek F, Galey JB, Rigneault H. Quantitative 3D molecular cutaneous absorption in human skin using label free nonlinear microscopy. J Control Release 2015;200:78-86.

26. Bharkatiya M, Nema R. Skin penetration enhancement techniques. J Young Pharm 2009;1:110.

27. Williams C, Barry BW. Penetration enhancers. Adv Drug Deliv Rev 2012;64:128-37.

28. El-Housiny S, Eldeen MA, El-Attar YA, Salem HA, Attia D, Bendas ER, et al. Fluconazole-loaded solid lipid nanoparticles topical gel for treatment of pityriasis versicolor: Formulation and clinical study. Drug Deliv 2018:25:78-90.

29. Changez M, Varshney M, Chander J, DindaAK. Effect of the composition of lecithin/n-propanol/isopropyl myristate/water microemulsions on barrier properties of mice skin for transdermal permeation of tetracaine 
hydrochloride: In vitro. Colloids Surf B Biointerfaces 2006;50:18-25.

30. Kogan A, Garti N. Microemulsions as transdermal drug delivery vehicles. Adv Colloid Interface Sci 2006;123:369-85.

31. Lopes LB. Overcoming the cutaneous barrier with microemulsions. Pharmaceutics 2014;6:52-77.

32. Muzaffar FA, Singh UK, Chauhan LA. Review on microemulsion as futuristic drug delivery Int J Pharm Pharm Sci 2013;5:39-53.

33. Lindman B, Danielson I. The definition of microemulsion. Colloid Surf 1981;3:391-2.

34. Callender SP, Mathews JA, Kobernyk K, Wettig SD. Microemulsion utility in pharmaceuticals: Implications for multi-drug delivery. Int $\mathrm{J}$ Pharm 2017;526:425-42.

35. Lawrence MJ, Rees GD. Microemulsion-based media as novel drug delivery systems. Adv Drug Deliv Rev 2000;45:89-121.

36. Kreilgaard M. Influence of microemulsions on cutaneous drug delivery. Adv Drug Deliv Rev 2002;54:S77-98.

37. Winsor PA. Hydrotropy, solubilisation and related emulsification processes. Trans Faraday Soc 1948;44:376-98.

38. Bhattacharya R, Mukhopadhyay S, Kothiyal P. Review on microemulsion-as a potential novel drug delivery system. World $\mathrm{J}$ Pharm Pharm Sci 2016;5:700-29

39. Singh PK, Iqubal MK, Shukla VK, Shuaib M. Microemulsions: Current trends in novel drug delivery systems. J Pharm Chem Biol Sci 2014;1:39-51.

40. Ghosh PK, Murthy RS. Microemulsions: A potential drug delivery system. Curr Drug Deliv 2006;3:167-80.

41. Talegaonkar S, Azeem A, Ahmad FJ, Khar RK, Pathan SA, Khan ZI. Microemulsions: A novel approach to enhanced drug delivery. Recent Pat Drug Deliv Formul 2008;2:238-57.

42. Aungst J. Novel formulation strategies for improving oral bioavailability of drugs with poor membrane permeation or presystemic metabolism. J Pharm Sci 1993;82:979-87.

43. Scolari PP, Gasco MR. Transdermal permeation of apomorphine through hairless mouse skin from microemulsions. Int J Pharm 2001;226:47-51.

44. Pradhan M, Singh D, Singh MR. Novel colloidal carriers for psoriasis: Current issues, mechanistic insight and novel delivery approaches. J Control Release 2013;170:380-95.

45. Sintov C, Shapiro L. New microemulsion vehicle facilitates percutaneous penetration in vitro and cutaneous drug bioavailability in vivo. J Control Release 2004;95:173-83.

46. Escribano A, Calpena C, Queralt J, Obach R, Doménech J. Assessment of diclofenac permeation with different formulations: Anti-inflammatory study of a selected formula. Eur J Pharm Sci 2003;19:203-10.

47. Trotta M, Ugazio E, Peira E, Pulitano C. Influence of ion pairing on topical delivery of retinoic acid from microemulsions. J Control Release 2003;86:315-21

48. Kahlweit M, Busse G, Faulhaber B. Preparing microemulsions with alkyl monoglucosides and the role of n-alkanols. Langmuir 1995;11:3382-7.

49. Gadhave D, Waghmare JT. A short review on microemulsion and its application in extraction of vegetable oil. Int $\mathrm{J}$ Res Eng Tech 2014;3:147-58.

50. Yin YM, Cui FD, Mu CF, Choi MK, Kim JS, Chung SJ, et al. Docetaxel microemulsion for enhanced oral bioavailability: Preparation and in vitro and in vivo evaluation. J Control Release 2009;140:86-94.

51. Zhao X, Liu JP, Zhang X, Li Y. Enhancement of transdermal delivery of theophylline using microemulsion vehicle. Int J Pharm 2006;327:58-64.

52. Djekic L, Primorac M. The influence of cosurfactants and oils on the formation of pharmaceutical microemulsions based on PEG-8 caprylic/ capric glycerides. Int J Pharm 2008;352:231-9.

53. Lawrence MJ. Surfactant systems: Microemulsions and vesicles as vehicles for drug delivery. Eur J Drug Metab Pharmacokinet 1994; 19:257-69.

54. Tenjarla S. Microemulsions: An overview and pharmaceutical applications. Crit Rev Ther Drug Carrier Syst 1999;16:461-521.

55. Alany RG, Rades T, Agatonovic-Kustrin S, Davies NM, Tucker IG. Effects of alcohols and diols on the phase behaviour of quaternary systems. Int J Pharm 2000;196:141-5.

56. Aboofazeli R, Lawrence CB, Wicks SR, Lawrence MJ. Investigations into the formation and characterization of phospholipid microemulsions. III. Pseudo-ternary phase diagrams of systems containing waterlecithin-isopropyl myristate and either an alkanoic acid, amine, alkanediol, polyethylene glycol alkyl ether or alcohol as cosurfactant. Int J Pharm 1994;111:63-72.

57. Alberti I, Kalia YN, Naik A, Bonny JD, Guy RH. Effect of ethanol and isopropyl myristate on the availability of topical terbinafine in human stratum corneum, in vivo. Int J Pharm 2001;219:11-9.

58. Peltola S, Saarinen-Savolainen P, Kiesvaara J, Suhonen TM, Urtti A. Microemulsions for topical delivery of estradiol. Int $\mathrm{J}$ Pharm 2003;254:99-107.

59. Hathout RM, Mansour S, Mortada ND, Geneidi AS, Guy RH. Uptake of microemulsion components into the stratum corneum and their molecular effects on skin barrier function. Mol Pharm 2010;7:1266-73.

60. Spernath A, Aserin A. Microemulsions as carriers for drugs and nutraceuticals. Adv Colloid Interface Sci 2006;128:47-64.

61. Surabhi O, Katare P, Sushma D. Lecithinised microemulsions for topical delivery of Tretinoin. Int J Drug Dev Res 2010;24:711-9.

62. Lee SY, Teo CC, Tan WJ, Lim HY, Lim HH, Teo SY. Lipid microemulsion-based hydrogels for effective topical delivery of phenytoin. Int J Pharm Pharm Sci 2016;8:240-6.

63. Liuzzi R, Carciati A, Guido S, Caserta S. Transport efficiency in transdermal drug delivery: What is the role of fluid microstructure? Colloids Surf B Biointerfaces 2016;139:294-305.

64. Jamal TD, Vyumvuhore R, Manfait M, Baillet-Guffroy A. Hydration effects on the barrier function of stratum corneum lipids: Raman analysis of ceramides 2, III and 5. Analyst 2013;138:6582-8.

65. Lademann PJ, Richter H, Darvin ME, Schanzer S, Thiede G, Sterry W, et al. In vivo investigations on the penetration of various oils and their influence on the skin barrier. Skin Res Technol 2012;18:364-9.

66. Bucks D, Maibach HI. Occlusion does not uniformly enhance penetration in vivo. Drugs Pharm Sci 1999;97:81-106.

67. Forster M, Bolzinger MA, Fessi H, Briancon S. Topical delivery of cosmetics and drugs. Molecular aspects of percutaneous absorption and delivery. Eur J Dermatol 2009;19:309-23.

68. Benson HA. Transdermal drug delivery: Penetration enhancement techniques. Curr Drug Deliv 2005;2:23-33.

69. Gupta RR, Jain SK, Varshney M. AOT water-in-oil microemulsions as a penetration enhancer in transdermal drug delivery of 5-fluorouracil. Colloids Surf B Biointerfaces 2005;41:25-32.

70. Yuan Y, Li SM, Mo FK, Zhong DF. Investigation of microemulsion system for transdermal delivery of meloxicam. Int J Pharm 2006;321:117-23.

71. Junyaprasert VB, Boonme P, Songkro S, Krauel K, Rades T. Transdermal delivery of hydrophobic and hydrophilic local anesthetics from o/w and w/o Brij 97-based microemulsions. J Pharm Pharm Sci 2007;10:288-98.

72. Junyaprasert VB, Boonme P, Wurster DE, Rades T. Aerosol OT microemulsions as carriers for transdermal delivery of hydrophobic and hydrophilic local anesthetics. Drug Deliv 2008;15:323-30.

73. Bergamante FV, Ceschel GC, Ronchi C, De Moraes CA. Control of transdermal permeation of hydrocortisone acetate from hydrophilic and lipophilic formulations. AAPS Pharm Sci Tech 2008;9:762-8.

74. Gannu R, Palem CR, Yamsani VV, Yamsani SK, Yamsani MR. Enhanced bioavailability of lacidipine via microemulsion based transdermal gels: Formulation optimization, ex vivo and in vivo characterization. Int $\mathrm{J}$ Pharm 2010;388:231-41.

75. Liu H, Chang FY, Hung DK. Terpene microemulsions for transdermal curcumin delivery: Effects of terpenes and cosurfactants. Colloids Surf B Biointerfaces 2011;82:63-70.

76. Sintov C. Transdermal delivery of curcumin via microemulsion. Int $\mathrm{J}$ Pharm 2015;481:97-103

77. Wang X, Xue M, Gu J, Fang X, Sha X. Transdermal microemulsion drug delivery system for impairing male reproductive toxicity and enhancing efficacy of Tripterygium wilfordii Hook f. Fitoterapia 2012;83:690-8.

78. Hathout RM, Nasr M. Transdermal delivery of betahistine hydrochloride using microemulsions: Physical characterization, biophysical assessment, confocal imaging and permeation studies. Colloids Surf B Biointerfaces 2013;110:254-60.

79. Al Abood RM, Talegaonkar S, Tariq M, Ahmad FJ. Microemulsion as a tool for the transdermal delivery of ondansetron for the treatment of chemotherapy induced nausea and vomiting. Colloids Surf B Biointerfaces 2013;101:143-51

80. Fouad SA, Basalious EB, El-Nabarawi MA, Tayel SA. Microemulsion and poloxamer microemulsion-based gel for sustained transdermal delivery of diclofenac epolamine using in-skin drug depot: In vitro in vivo evaluation. Int J Pharm 2013;453:569-78.

81. Mostafa M, Ammar NM, Abd El-Alim SH, El-anssary AA. Transdermal microemulsions of Glycyrrhiza glabra L.: Characterization, stability and evaluation of antioxidant potential. Drug Deliv 2014;21:130-9.

82. Mura P, Bragagni M, Mennini N, Cirri M, Maestrelli F. Development of liposomal and microemulsion formulations for transdermal delivery of clonazepam: Effect of randomly methylated $\beta$-cyclodextrin. Int $\mathrm{J}$ Pharm 2014;475:306-14 
83. Ge S, Lin Y, Lu H, Li Q, He J, Chen B, et al. Percutaneous delivery of econazole using microemulsion as vehicle: Formulation, evaluation and vesicle-skin interaction. Int J Pharm 2014;465:120-31.

84. Sapra SB, Tiwary AK. Microemulsion transdermal formulation for simultaneous delivery of valsartan and nifedipine: Formulation by design. AAPS Pharm Sci Tech 2016;18:1901-16.

85. Ren CL, Chen G. Formulation optimization and ex vivo and in vivo evaluation of celecoxib microemulsion based gel for transdermal delivery. AAPS Pharm Sci Tech 2016;18:1960-71.
86. Seok SH, Lee SA, Park ES. Formulation of a microemulsion-based hydrogel containing celecoxib. J Drug Deliv Sci Technol 2017;4:459-71.

87. Yehia R, Hathout RM, Attia DA, Elmazar MM, Mortada ND. Antitumor efficacy of an integrated methyl dihydrojasmonate transdermal microemulsion system targeting breast cancer cells: In vitro and in vivo studies. Colloids Surf B Biointerfaces 2017;155:512-21.

88. Alyoussef AJ, Talhouni AA. In vivo and in vitro study of transdermal application of diclofenac sodium using nonionic microemulsions as colloidal drug delivery systems. J Drug Deliv Sci Technol 2018;43:27-33. 